\title{
Assessment of Weight Management Practices among Adults in the United Arab Emirates
}

\author{
Amita Attlee, ${ }^{1,2,3}$ Nour Atmani, ${ }^{1}$ Viktor Stromtsov, ${ }^{1}$ Fatima Ali, ${ }^{1}$ Rim Tikarly, ${ }^{1}$ \\ Sarah Ryad, ${ }^{1}$ Ghada Salah, ${ }^{1}$ Hayder Hasan, ${ }^{1,3}$ and Reyad Obaid ${ }^{1,3}$ \\ ${ }^{1}$ Department of Clinical Nutrition and Dietetics, College of Health Sciences, University of Sharjah, Sharjah, UAE \\ ${ }^{2}$ Nutrition and Health Department, College of Food and Agriculture, United Arab Emirates University, P.O. Box 15551, Al Ain, UAE \\ ${ }^{3}$ Research Institute for Medical and Health Sciences, University of Sharjah, Sharjah, UAE
}

Correspondence should be addressed to Amita Attlee; aattlee@sharjah.ac.ae

Received 15 June 2017; Accepted 16 August 2017; Published 24 September 2017

Academic Editor: Michael B. Zemel

Copyright (C) 2017 Amita Attlee et al. This is an open access article distributed under the Creative Commons Attribution License, which permits unrestricted use, distribution, and reproduction in any medium, provided the original work is properly cited.

With a rise in global incidence of overweight and obesity, the number of patients seeking weight management (WM) advice is likely to increase. Our aim was to explore the prevalence of WM practices and investigate association of WM goals with sociodemographic variables and practices among United Arab Emirates (UAE) adults. An exploratory, cross-sectional research was conducted on 1275 adult males and females, residing in UAE. A structured questionnaire was administered. WM goals to lose/maintain/gain weight were reported in $88.3 \%$ participants. WM goals were significantly associated with age, sex, marital status, education, current body weight perception, and medical condition. Out of 21 selected WM practices, popular strategies included increasing physical activity (52.9\%), eating less fat (51.1\%), consuming fewer calories (43.3\%), joining gym (27.5\%), skipping meals (26.1\%), and consuming natural herbs and teas (20.7\%). Visiting dietitian (12.3\%) ranked ninth in the order of preference. Males focused on physical activity, gyms, and wellness centers and females on calories counting, dietitian visits, meals replacement, skipping meals, and natural herbs/teas. Married adults reported eating less fat ( $54.3 \%$ versus $47.3 \%, p=0.020)$; singles opted calories counting, gyms, and meals replacement. Frequent referral sources were friends (37.8\%) and Internet (32.1\%). Most UAE adults had WM goals that were associated with sociodemographic variables and WM practices. Awareness about the ill-effects of unhealthy WM practices and importance of dietitian's consultation are imperative.

\section{Introduction}

American Medical Association (2013) resolved that obesity should be considered as a chronic medical disease state [1]. With the global incidence of overweight and obesity among adults continuing to rise, the number of patients seeking advice for weight management (WM) is likely to increase. Recent estimates on the prevalence of overweight and obesity are astounding in Arabian Gulf countries particularly in Kuwait, Qatar, Saudi Arabia, and Bahrain where between two-thirds to three-quarters of adults and adolescents are overweight or obese [2]. Approximately $75 \%$ of people in the UAE are obese or overweight [3]. On the other hand, poor nutrition results in undernutrition that is evident as the state of underweight. Nearly $3.9 \%$ of Emirati women were found to be underweight according to the National Nutrition Survey in the UAE [4]. Significant weight loss in people tempts them to try varied strategies of weight gain. Attempts to lose, maintain, or gain weight are common practices among individuals. However, the strategies to achieve these goals vary. Some prefer diets prescribed by dietitians, while others follow "popular" or "fad" diets encouraging irrational and, sometimes, unsafe practices [5]. A plethora of WM services are available in the UAE ranging from weight-loss/fitness centers to bariatric surgeries; however, statistics on their usage and client registries are not yet established.

Dietitians take the lead in the promotion of public health nutrition through the blend of scientific knowledge and understanding of social and cultural factors that influence what people eat [6]. However, individuals typically select WM practices that they feel most comfortable trying, fit into their budget, and are reasonably likely to be successful. The variety 
of practices adopted for WM ranges from commercial to medical and surgical approaches [7].

Reduction in total caloric intake, skipping meals, fasting $\geq 24$ hours, taking diet pills or diuretics, and joining weightloss programs [8]; increasing physical activity, eating diet foods or products, drinking a lot of water, and following a special diet [9]; or using meal replacements are common strategies utilized to achieve the desired WM goals. Moreover, bariatric surgery has been demonstrated to be the most effective and long term treatment for individuals with severe obesity or moderate obesity complicated by comorbid conditions that is not responsive by nonsurgical approaches [7]. Making diet and lifestyle changes can be difficult, turning many people to dietary supplements for weight loss in the hope that these products will help them more easily achieve their weight-loss goals. These supplements encompass a wide variety of products and come in a variety of forms, including capsules, tablets, liquids, powders, and bars [10]. Using pharmacological agents as adjuvant therapy after lifestyle intervention to maintain the weight loss achieved is popular for weight loss and prevention of regain [11]. For underweight individuals, appetite stimulants and commercial drugs are accessible for weight gain and optimum body shape [12].

Potentially harmful weight control practices were reported in females including excessive exercise, starvations, purging, laxatives, slimming tablets, and smoking for weight control, while males used excessive exercise, starvation, and smoking to lose or maintain weight [13].

Different WM practices adopted by individuals are associated with several factors such as age and gender $[8,14,15]$, education level [16], marital status [17], socioeconomic status [18], peer pressure, and health issues. Women's but not men's marital roles appear to influence their perceived and desired weight, suggesting that weight management interventions should be sensitive to both marital status and gender differences [17]. Further, high income individuals were more likely to recognize being overweight and were more likely to attempt weight control [18]. However, unhealthy WM strategies may lead to stunted growth, nutrient deficiencies, infections, clinically significant eating disorders, increased risks of osteoporosis, and anemia [19]. There is a lack of evidence on WM practices and their determinants among adults residing in the UAE.

The aim of this study was to explore the prevalence of WM practices and investigate the association of WM goals with sociodemographic variables and practices among adult residents in the UAE.

\section{Material and Methods}

An exploratory study with a cross-sectional research design was conducted. Sample size was calculated based on the estimate of $70 \%$ prevalence of overweight and obesity in UAE adult population [3] with $90 \%$ confidence. A total of 1275 males and females aged 18 years or above residing in the seven Emirates of the UAE (Abu Dhabi, Dubai, Sharjah, Ajman, Fujrairah, Ras Al Khaimah, and Umm Al Quwain) participated in the study. These participants were selected from a free living population in UAE through convenience sampling method from different malls, hyper- and supermarkets, institutions, and neighborhood. The research team members approached the prospective participants and briefed them on the purpose of study and if they expressed interest, they were requested to sit in a calm area with the researcher for further formalities and participation. A structured questionnaire was adapted [16] and modified for clarity and cultural applicability after being pilot tested on 12 adults who were not included in the study sample. It consisted of sections to collect information on sociodemographic profiles, body weight perception and medical conditions, WM goals and practices, sources of referrals for adoption of WM practices, and duration and outcomes of adopted WM practices. Twenty-one common WM practices were included that could cover the broad spectrum WM goals of losing, maintaining, or gaining body weight. Pregnant women were excluded from participation in this study. The protocol was approved by the research committee, Clinical Nutrition and Dietetics Department, College of Health Sciences, University of Sharjah (number 4/11/2013). Informed written consent was taken before administering the questionnaire and participant anonymity was maintained.

Data analysis was carried out using the Statistical Package for the Social Sciences Software (SPSS version 17.0, IBM, USA). Descriptive statistics of frequencies and percentages were used to determine the prevalence of WM among adults in the UAE. Chi-square was used to assess the association of independent variables such as age, sex, nationality, marital status, income, and WM practices and the dependent variable, WM goals. Age cut-off at 45 years was considered since the trend of overweight and obesity changes around 45 years of age in Gulf Cooperation Council countries [20, 21]. The data was tested for significance at $p<0.05$.

\section{Results}

At the time of survey period, most of the participants reported having a WM goal. Out of 1275 participants, 1126 (88.3\%) participants had a WM goal and 149 (11.7\%) participants neither were concerned about their body weights nor reported any WM goal at the time of survey. Out of 1126 (those who had a WM goal), $624(55.4 \%)$ of them were trying to lose weight and $408(36.2 \%)$ reported having a WM goal to maintain weight, while $94(8.4 \%)$ participants were attempting to gain weight. Results below are presented for those 1126 participants who had a WM goal.

Sociodemographic characteristics (Table 1) showed that the majority of participants (83.1\%) were below the age of 45 years; $58.4 \%$ were females and $41.6 \%$ males. More than half (53.1\%) of the participants were married and the rest (46.9\%) were singles. Emirati nationals constituted $15.9 \%$ of the 1126 participants, while remaining $84.1 \%$ were expatriates from other nationalities. Out of 1126 participants, $897(79.7 \%)$ had completed higher education; almost two-thirds (736/1126) of the participants reported monthly income of less than AED 20,000 (equivalent to USD 5,450). All sociodemographic variables, except nationality and monthly income, were found to be significantly associated with the WM goals. 
TABLE 1: Associations between sociodemographic characteristics and weight management goals among UAE adults (Chi-square test).

\begin{tabular}{|c|c|c|c|c|c|}
\hline \multirow{3}{*}{ Sociodemographic variable } & \multicolumn{5}{|c|}{ Weight management goal } \\
\hline & $\begin{array}{c}\text { Total } \\
N=1126\end{array}$ & $\begin{array}{c}\text { Lose weight } \\
N=624\end{array}$ & $\begin{array}{c}\text { Maintain weight } \\
\qquad N=408\end{array}$ & $\begin{array}{c}\text { Gain weight } \\
N=94\end{array}$ & $p$ value \\
\hline & $N(\%)$ & $N(\%)$ & $N(\%)$ & $N(\%)$ & \\
\hline \multicolumn{6}{|l|}{ Age group (years) } \\
\hline$<45$ & $936(83.1)$ & $499(80)$ & $348(85.3)$ & $89(94.7)$ & \multirow{2}{*}{0.001} \\
\hline$\geq 45$ & $190(16.9)$ & $125(20)$ & $60(14.7)$ & $5(5.3)$ & \\
\hline \multicolumn{6}{|l|}{ Sex } \\
\hline Male & $468(41.6)$ & $219(35.1)$ & $197(48.3)$ & $52(55.3)$ & \multirow{2}{*}{$<0.001$} \\
\hline Female & $658(58.4)$ & $405(64.9)$ & $211(51.7)$ & $42(44.7)$ & \\
\hline \multicolumn{6}{|l|}{ Marital status } \\
\hline Single & $528(46.9)$ & $277(44.4)$ & $182(44.6)$ & $69(73.4)$ & \multirow{2}{*}{$<0.001$} \\
\hline Married & $598(53.1)$ & $347(55.6)$ & $226(55.4)$ & $25(26.6)$ & \\
\hline \multicolumn{6}{|l|}{ Nationality } \\
\hline UAE national & $179(15.9)$ & $102(16.3)$ & $61(15.0)$ & $16(17.0)$ & \multirow{2}{*}{0.792} \\
\hline UAE nonnational & $947(84.1)$ & $522(83.7)$ & $347(85.0)$ & $78(83.0)$ & \\
\hline \multicolumn{6}{|l|}{ Education } \\
\hline Up to high school & $229(20.3)$ & $146(23.4)$ & $65(15.9)$ & $18(19.1)$ & \multirow{2}{*}{0.014} \\
\hline Graduate or above & $897(79.7)$ & $478(76.6)$ & $343(84.1)$ & $76(80.9)$ & \\
\hline \multicolumn{6}{|l|}{ Income (AED) } \\
\hline$<20,000$ & $736(65.4)$ & 397 (63.6) & $273(66.9)$ & $66(70.2)$ & \multirow{2}{*}{0.321} \\
\hline$>20,000$ & $390(34.6)$ & $227(36.4)$ & $135(33.1)$ & $28(29.8)$ & \\
\hline
\end{tabular}

Comparatively, a significant higher proportion of younger adult population $(p=0.001)$, females $(p<0.001)$, and married $(p<0.001)$ adults reported having WM goals. Higher education status was also found to be significantly associated with the WM goals $(p=0.014)$.

It was interesting to note that the WM goals of the participants were significantly associated with their perception of current body weight $(p<0.001)$. Overall, 595 (52\%) participants perceived themselves with "normal weight" followed by 417 (37\%) as "overweight" and 66 (5.9\%) as "underweight" and $58(5.1 \%)$ perceived their current body weight as "obese." Comparatively, majority of the participants with the goal to lose weight perceived their body weight as "overweight" $(382 / 624 ; 61.2 \%)$; majority of those who aimed to maintain weight perceived themselves as "normal" weight (359/408; $88 \%$ ) and most of those who had the goal to gain weight perceived that they were "underweight" (46/94; 48.9\%).

There was a significant association in the WM goal and medical condition of the participants. High cholesterol, hypertension, and diabetes mellitus were self-reported in $12.5 \%(n=141 ; p<0.001), 11.5 \%(n=129 ; p<0.001)$ and $10.2 \%(n=115 ; p=0.04)$ participants, respectively. Almost three-fourths $(68.7 \%-76.7 \%)$ of the participants with positive self-reporting of any of these medical conditions had a WM goal of losing weight; $20.2 \%-25.2 \%$ had a goal of weight maintenance; and $4.3 \%-7.4 \%$ participants aimed towards gaining weight.

Table 2 shows the distribution of 1126 participants according to the selected $21 \mathrm{WM}$ practices adopted by them during the study period. Six popular strategies emerged including increasing physical activity by enhancing movements of skeletal muscles, not necessarily following an organized regime $(52.9 \%)$, eating less fat $(51.1 \%)$, consuming fewer calories $(43.3 \%)$, joining gym to increase physical activity through exercises in a controlled environment $(27.5 \%)$, skipping meals $(26.1 \%)$, and consuming natural herbs and teas $(20.7 \%)$. Visiting a dietitian was not reported as a common WM practice with $12.3 \%$ (138/1126) participants stating that they visited a dietitian, ranking ninth in the order of preference. Fourteen out of 21 selected WM practices were found to have a significant association with the WM goals of the participants. On the other hand, practices such as joining gyms and wellness centers, supplements use and pharmacotherapy, and bariatric surgery as well as subscribing special diets were independent of the WM goal.

Further, significant associations between sociodemographic variables (sex, marital status, and nationality) and WM practices among UAE adults are presented in Table 3. As evident, a significantly higher proportion of males than females reported to have increased physical activity (57.5\% versus $49.7 \%, p=0.011)$ and joined gyms $(34.8 \%$ versus $22.3 \%, p<0.001)$ and wellness centers (11.8 versus $7.6 \%, p$ $=0.022$ ) for management of their weights. In contrast, more females than males either consumed fewer calories $(47.0 \%$ versus $38.2 \%, p=0.004)$, skipped meals ( $28.6 \%$ versus $22.6 \%$, $p=0.028)$, consumed natural herbs and teas $(23.3 \%$ versus $17.1 \%, p=0.014)$, visited a dietitian $(14.1 \%$ versus $9.6 \%, p=$ $0.027)$, or counted calories $(8.2 \%$ versus $3.4 \%, p=0.001)$. 
TABLE 2: Associations between weight management practices and weight management goals among UAE adults (Chi-square test).

\begin{tabular}{|c|c|c|c|c|c|}
\hline \multirow{3}{*}{ Weight management practice } & \multicolumn{5}{|c|}{ Weight management goal } \\
\hline & Total & Lose weight & Maintain weight & Gain weight & $p$ value \\
\hline & $N(\%)$ & $N(\%)$ & $N(\%)$ & $N(\%)$ & \\
\hline \multicolumn{6}{|l|}{ Increasing physical activity } \\
\hline Yes & $596(52.9)$ & $344(55.1)$ & $214(52.5)$ & $38(40.4)$ & \multirow{2}{*}{0.028} \\
\hline No & $530(47.1)$ & $280(44.9)$ & $194(47.5)$ & $56(59.6)$ & \\
\hline \multicolumn{6}{|l|}{ Eating less fat } \\
\hline Yes & $575(51.1)$ & $363(58.2)$ & $194(47.5)$ & $18(19.1)$ & \multirow{2}{*}{$<0.001$} \\
\hline No & $551(48.9)$ & $261(41.8)$ & $214(52.5)$ & $76(80.9)$ & \\
\hline \multicolumn{6}{|l|}{ Consuming fewer calories } \\
\hline Yes & $488(43.3)$ & $335(53.7)$ & $142(34.8)$ & $11(11.7)$ & \multirow{2}{*}{$<0.001$} \\
\hline No & $638(56.7)$ & $289(46.3)$ & $266(65.2)$ & $83(88.3)$ & \\
\hline \multicolumn{6}{|l|}{ Joining gym } \\
\hline Yes & $310(27.5)$ & $165(26.4)$ & $113(27.7)$ & $32(34.0)$ & \multirow{2}{*}{0.305} \\
\hline No & $816(72.5)$ & $459(73.6)$ & $295(72.3)$ & $62(66.0)$ & \\
\hline \multicolumn{6}{|l|}{ Skipping meals } \\
\hline Yes & $294(26.1)$ & $202(32.4)$ & $90(22.1)$ & $2(2.1)$ & \multirow{2}{*}{$<0.001$} \\
\hline No & $832(73.9)$ & $422(67.6)$ & $318(77.9)$ & $92(97.9)$ & \\
\hline \multicolumn{6}{|l|}{ Taking natural herbs and teas } \\
\hline Yes & $233(20.7)$ & $141(22.6)$ & $87(21.3)$ & $5(5.3)$ & \multirow{2}{*}{0.001} \\
\hline No & $893(79.3)$ & $483(77.4)$ & $321(78.7)$ & $89(94.7)$ & \\
\hline \multicolumn{6}{|l|}{$\begin{array}{l}\text { Taking special supplements for } \\
\text { weight management }\end{array}$} \\
\hline Yes & $193(17.1)$ & $110(17.6)$ & $69(16.9)$ & $14(14.9)$ & \multirow{2}{*}{0.797} \\
\hline No & $933(82.9)$ & $514(82.4)$ & $339(83.1)$ & $80(85.1)$ & \\
\hline \multicolumn{6}{|l|}{ Following a popular (fad) diet } \\
\hline Yes & $149(13.2)$ & $100(16.0)$ & $45(11.0)$ & $4(4.3)$ & \multirow{2}{*}{0.002} \\
\hline No & $977(86.8)$ & $524(84.0)$ & $363(89.0)$ & $90(95.7)$ & \\
\hline \multicolumn{6}{|l|}{ Visiting a dietitian } \\
\hline Yes & $138(12.3)$ & $96(15.4)$ & $31(7.6)$ & $11(11.7)$ & \multirow{2}{*}{0.001} \\
\hline No & $988(87.7)$ & $528(84.6)$ & $377(92.4)$ & $83(88.3)$ & \\
\hline \multicolumn{6}{|l|}{ Fasting } \\
\hline Yes & $118(10.5)$ & $81(13.0)$ & $37(9.1)$ & $0(0.00)$ & \multirow{2}{*}{$<0.001$} \\
\hline No & $1008(89.5)$ & $543(87.0)$ & $371(90.9)$ & $94(100.0)$ & \\
\hline Joining wellness centre & & & & & \\
\hline Yes & $105(9.3)$ & $62(9.9)$ & $31(7.6)$ & $12(12.8)$ & 0.220 \\
\hline No & $1021(90.7)$ & $562(90.1)$ & $1021(90.7)$ & $82(87.2)$ & 0.220 \\
\hline Replacement foods & & & & & \\
\hline Yes & $76(6.7)$ & $32(5.1)$ & $31(7.6)$ & $13(13.8)$ & 0.005 \\
\hline No & $1050(93.3)$ & $592(94.9)$ & $377(92.4)$ & $81(86.2)$ & \\
\hline Counting calories & & & & & \\
\hline Yes & $70(6.2)$ & $50(8.0)$ & $17(4.2)$ & $3(3.2)$ & 0.020 \\
\hline No & $1056(93.8)$ & $574(92.0)$ & $391(95.8)$ & $91(96.8)$ & 0.020 \\
\hline Using pharmacotherapy & & & & & \\
\hline Yes & $56(5.0)$ & $32(5.1)$ & $21(5.1)$ & $3(3.2)$ & 0.708 \\
\hline No & $1070(95.0)$ & $592(94.9)$ & $387(94.9)$ & $91(96.8)$ & 0.100 \\
\hline Consuming more calories & & & & & \\
\hline Yes & $53(4.7)$ & $7(1.1)$ & $12(2.9)$ & $34(36.2)$ & $<0.001$ \\
\hline No & $1073(95.3)$ & $617(98.9)$ & $396(97.1)$ & $60(63.8)$ & $<0.001$ \\
\hline
\end{tabular}


TABLE 2: Continued.

\begin{tabular}{|c|c|c|c|c|c|}
\hline \multirow[b]{2}{*}{ Weight management practice } & \multicolumn{5}{|c|}{ Weight management goal } \\
\hline & $\begin{array}{l}\text { Total } \\
N(\%)\end{array}$ & $\begin{array}{c}\text { Lose weight } \\
\qquad N(\%)\end{array}$ & $\begin{array}{c}\text { Maintain weight } \\
\qquad N(\%)\end{array}$ & $\begin{array}{c}\text { Gain weight } \\
N(\%)\end{array}$ & $p$ value \\
\hline \multicolumn{6}{|l|}{ Taking appetite stimulants } \\
\hline Yes & $39(3.5)$ & $6(1.0)$ & $15(3.7)$ & $18(19.1)$ & \multirow{2}{*}{$<0.001$} \\
\hline No & $1087(96.5)$ & $618(99.0)$ & $393(96.3)$ & $76(80.9)$ & \\
\hline \multicolumn{6}{|l|}{ Purging (vomiting) } \\
\hline Yes & $37(3.3)$ & $30(4.8)$ & $6(1.5)$ & $1(1.1)$ & \multirow{2}{*}{0.006} \\
\hline No & $1089(96.7)$ & $594(95.2)$ & $402(98.5)$ & $93(98.9)$ & \\
\hline \multicolumn{6}{|l|}{ Eating more fat } \\
\hline Yes & $37(3.3)$ & $5(0.8)$ & $6(1.5)$ & $26(27.7)$ & \multirow{2}{*}{$<0.001$} \\
\hline No & $1089(96.7)$ & $619(99.2)$ & $402(98.5)$ & $68(72.3)$ & \\
\hline \multicolumn{6}{|l|}{ Subscribing a special diet } \\
\hline Yes & $34(3.0)$ & $20(3.2)$ & $10(2.5)$ & $4(4.3)$ & \multirow{2}{*}{0.602} \\
\hline No & $1092(97.0)$ & $604(96.8)$ & $398(97.5)$ & $90(95.7)$ & \\
\hline \multicolumn{6}{|l|}{ Others } \\
\hline Yes & $11(1.0)$ & $5(0.8)$ & $5(1.2)$ & $1(1.1)$ & \multirow{2}{*}{0.792} \\
\hline No & $1115(99.0)$ & $619(99.2)$ & $403(98.8)$ & $93(98.9)$ & \\
\hline \multicolumn{6}{|l|}{ Bariatric surgery } \\
\hline Yes & $6(0.5)$ & $4(0.6)$ & $2(0.5)$ & $0(0.00)$ & \multirow{2}{*}{0.721} \\
\hline No & $1120(99.5)$ & $620(99.4)$ & $406(99.5)$ & $94(100.0)$ & \\
\hline
\end{tabular}

Marital status was also found to be significantly associated with certain WM practices (Table 3). While married participants reported eating less fat $(54.3 \%$ versus $47.3 \%, p=0.020)$ for managing their weights, significantly higher proportions of participants with single marital status reported either focusing on their calories consumption, joining gyms, or meal replacement compared to their married counterparts.

Besides, Table 3 highlights that a significantly higher proportion of UAE nationals (17.3\%) reported visiting the dietitian for managing weights in contrast to $11.3 \%$ expatriate participants $(p=0.024)$. On the other hand, $7.2 \%$ expatriates in comparison with $1.1 \%$ nationals reported counting calories to manage their body weights $(p=0.001)$.

Participants reported different sources of referrals for the adoption of their WM practices: friends (37.8\%), Internet (32.1\%), dietitians $(23.5 \%)$, television $(23.1 \%)$, gym instructors $(23.0 \%)$, and doctors/physicians (21.0\%). Lesser referred sources included relatives (18.7\%), magazines (18.4\%), newspapers $(12.9 \%)$, radio $(9.5 \%)$, and neighbors $(6.1 \%)$.

Duration of adoption of current WM practices varied in the 1126 participants: while 36.8\% $(n=414)$ reported that they adopted the current strategies since less than last 3 months, $27.8 \%(n=313)$ were practicing the reported WM strategies for more than 12 months, followed by $22.4 \%$ $(n=252)$ for the last 3-6 months. Only 11.5\% $(n=130)$ participants reported that their current WM practices were adopted for the last 6-12 months from the survey period. However, the rest $(n=17)$ did not respond to the duration of adoption of WM practices.

The outcome of adopted WM practices was reported in terms of the change in body weight during the period by 1095 out of 1126 participants. Out of those who responded, $63.6 \%$ (696/1095) reported less than $5 \mathrm{~kg}$ change in weight, $28.9 \%$ $(317 / 1095)$ between 5 and $10 \mathrm{~kg}, 5.3 \%$ (58/1095) more than $10-15 \mathrm{~kg}$, and $2.2 \%(24 / 1095)$ reported a change of more than $15 \mathrm{~kg}$ in body weight.

\section{Discussion}

Our results emphasized that the practices were associated with the WM goals in adults. Most common WM practices found in the present study included increasing physical activity, eating less fat, and consuming fewer calories. Lin et al. (2013) reported exercise to be a more common method than switching to foods with lower calories for losing weight [9]. Further, Kruger et al. (2004) found that only one-third of all those people who were trying to lose weight reported eating less calories and exercising more as the strategies [8]. Visiting dietitian was not a common WM practice and ranked ninth in the order of participants' preferences in our study. Spikmans et al. (2003) reported that one in three patients with diabetes attending the out-patient clinics skipped one or more visits to their dietitian [22]. Primary care physicians continue to believe that providing nutrition counseling is within their realm of responsibility; patients seemed to expect dietary counseling from their physician rather than from dietitians [23], and most patients reported apprehension and doubt towards the usefulness of dietary advice from dietitians [22].

The present study highlighted that a significantly higher percentage of females (58.4\%) than males (41.6\%) had a WM goal. Similar trend was reported by Kruger et al. (2004), wherein $24 \%$ of men and $38 \%$ of women were trying to 
TABLE 3: Significant associations between sociodemographic variables (sex, marital status, and nationality) and weight management practices among UAE adults (Chi-square test).

\begin{tabular}{|c|c|c|c|c|}
\hline Weight management practice & $\begin{array}{c}\text { Total } \\
N=1126 \\
N(\%)\end{array}$ & $\begin{array}{c}\text { Males } \\
N=468 \\
N(\%)\end{array}$ & $\begin{array}{c}\text { Females } \\
N=658 \\
N(\%)\end{array}$ & $p$ value \\
\hline \multicolumn{5}{|l|}{ Increasing physical activity } \\
\hline Yes & $596(52.9)$ & $269(57.5)$ & $327(49.7)$ & \multirow{2}{*}{0.011} \\
\hline No & $530(47.1)$ & $199(42.5)$ & $331(50.3)$ & \\
\hline \multicolumn{5}{|l|}{ Consuming fewer calories } \\
\hline Yes & $488(43.3)$ & $179(38.2)$ & $309(47.0)$ & \multirow{2}{*}{0.004} \\
\hline No & $638(56.7)$ & $289(61.8)$ & $349(53.0)$ & \\
\hline \multicolumn{5}{|l|}{ Joining gym } \\
\hline Yes & $310(27.5)$ & $163(34.8)$ & $147(22.3)$ & \multirow{2}{*}{$<0.001$} \\
\hline No & $816(72.5)$ & $305(65.2)$ & $511(77.7)$ & \\
\hline \multicolumn{5}{|l|}{ Skipping meals } \\
\hline Yes & $294(26.1)$ & $106(22.6)$ & $188(28.6)$ & \multirow{2}{*}{0.028} \\
\hline No & $832(73.9)$ & $362(77.4)$ & $470(71.4)$ & \\
\hline \multicolumn{5}{|l|}{ Taking natural herbs and teas } \\
\hline Yes & $233(20.7)$ & $80(17.1)$ & $153(23.3)$ & \multirow{2}{*}{0.014} \\
\hline No & $893(79.3)$ & $388(82.9)$ & $505(76.7)$ & \\
\hline \multicolumn{5}{|l|}{ Visiting a dietitian } \\
\hline Yes & $138(12.3)$ & $45(9.6)$ & $93(14.1)$ & \multirow{2}{*}{0.027} \\
\hline No & $988(87.7)$ & $423(90.4)$ & $565(85.9)$ & \\
\hline \multicolumn{5}{|l|}{ Joining wellness centre } \\
\hline Yes & $105(9.3)$ & $55(11.8)$ & $50(7.6)$ & \multirow{2}{*}{0.022} \\
\hline No & $1021(90.7)$ & $413(88.2)$ & $608(92.4)$ & \\
\hline \multicolumn{5}{|l|}{ Counting calories } \\
\hline Yes & $70(6.2)$ & $16(3.4)$ & $54(8.2)$ & \multirow{2}{*}{0.001} \\
\hline No & $1056(93.8)$ & $452(96.6)$ & $604(91.8)$ & \\
\hline \multirow{2}{*}{ Weight management practice } & $\begin{array}{c}\text { Total } \\
N=1126\end{array}$ & $\begin{array}{c}\text { Single } \\
N=528\end{array}$ & $\begin{array}{l}\text { Married } \\
N=598\end{array}$ & \multirow{2}{*}{$p$ value } \\
\hline & $N(\%)$ & $N(\%)$ & $N(\%)$ & \\
\hline \multicolumn{5}{|l|}{ Eating less fat } \\
\hline Yes & $575(51.1)$ & $250(47.3)$ & $325(54.3)$ & \multirow{2}{*}{0.020} \\
\hline No & $551(48.9)$ & $278(52.7)$ & $273(45.7)$ & \\
\hline \multicolumn{5}{|l|}{ Consuming more calories } \\
\hline Yes & $53(4.7)$ & $32(6.1)$ & $21(3.5)$ & \multirow{2}{*}{0.049} \\
\hline No & $1073(95.3)$ & $496(93.9)$ & $577(96.5)$ & \\
\hline \multicolumn{5}{|l|}{ Joining gym } \\
\hline Yes & $310(27.5)$ & $176(33.3)$ & $134(22.4)$ & \multirow{2}{*}{$<0.001$} \\
\hline No & $816(72.5)$ & $352(66.7)$ & $464(77.6)$ & \\
\hline \multicolumn{5}{|l|}{ Counting calories } \\
\hline Yes & $70(6.2)$ & $54(10.2)$ & $16(2.7)$ & \multirow{2}{*}{$<0.001$} \\
\hline No & $1056(93.8)$ & $474(89.8)$ & $582(97.3)$ & \\
\hline Replacement meals & & & & \\
\hline Yes & $76(6.7)$ & $47(8.9)$ & $29(4.8)$ & \\
\hline No & $1050(93.3)$ & $481(91.1)$ & $569(95.2)$ & 0.009 \\
\hline
\end{tabular}


TABLE 3: Continued.

\begin{tabular}{lccc}
\hline & Total & UAE National & Non-UAE National \\
Weight management practice & $N=1126$ & $N=179$ & $N=-947$ \\
& $N(\%)$ & $N(\%)$ & $N(\%)$
\end{tabular}

lose weight [8]. Sex-wise analysis of our study showed that more females than males counted or reduced calories, visited dietitian, and consumed natural herbs and teas. Skipping meals was also reported more in women than men. Serdula et al. (1994) revealed that the women were more likely than men to report counting calories, belonging to an organized weight-loss program, taking special supplements, or taking diet pills. The use of these specific weight control practices was lower for those who were trying to maintain weight [16]. Kruger et al. (2004) also supported that more women than men adopted eating fewer calories, eating less fat, eating food supplements, joining a weight-loss program, taking diet pills and diuretics, or fasting as the strategies to lose weight [8].

Our study revealed that the WM goal was independent of income. However, income was a significant predictor of whether or not overweight or obese adults receive weightloss advice [24]. Though the UAE nationals constitute about $11 \%$ of the country's population [25], it was evident that a higher proportion of UAE nationals visited a dietitian than the UAE nonnationals. This might be attributed to the fact that UAE nationals have access to free health care and would visit the dietitian to get appropriate WM strategies. Refusal of insurance companies to reimburse dietetic counseling continues to be a barrier for the utilization of these services [26]. Evidence from United States clearly states that the utilization of dietetic services has increased ever since the policy of reimbursement for dietary counseling by registered dietitian under multidisciplinary approach as a medical benefit was introduced [27].

Overall, more married adults reported having WM goals of either losing weight or maintaining weight. In contrast, significantly higher number of participants with single marital status had the WM goal to gain weight. Further, more participants with single marital status practiced counting calories, joining gym, and consuming replacement meals than those married. Earlier, Klos and Sobal (2013) analyzed that marital status was unrelated to WM approach, except that divorced or separated women were more likely to have intentionally lost weight within the past year as compared to never married women. Additionally, never married men were more likely to be attempting to prevent weight gain than married or cohabiting men [17].

Most referred source of information for a WM approach in the present study was "friends" and "Internet." This might have been one of the reasons for the participants to have followed unhealthy WM practices, as information might be distorted and incorrect. A study from the Gulf involving Emirati and Omani adults with diabetes revealed that onefourth of the patients relied on informal networks such as friends and family for nutrition information [28].

The present study had some inherent limitations due to logistic reasons. The sampling was based on convenience rather than randomization. However, it was ensured that the participants were recruited from all the seven Emirates in proportion aligning the national population distribution. Further, information was gathered on perceived and not actual body weights. Yet, interesting findings emerged indicating that majority of the participants perceived themselves as having "normal" body weights. This may be one of the barriers for adults in losing weight in an otherwise "overweight/obese" country. Considering an exploratory nature of this study, it highlighted common WM practices and important sociodemographic determinants associated with WM goals among adults residing in the UAE.

\section{Conclusion}

Adults residing in the UAE generally have a WM goal and they adopt a variety of WM practices to achieve their goals. Unhealthy practices for WM such as skipping meals, following a popular diet, and pharmacotherapy are witnessed among the UAE adult population while visiting the dietitian is not a common practice. This poses important concerns on the nutrition knowledge and motivation of the individuals and competence of the dietitians as well as the cost and reimbursement policy of the dietitian's consultation by health insurance.

Awareness is required in the UAE about the ill-effects of unhealthy WM practices and importance of dietitian's consultation to achieve the desired WM goals in a safe and healthy way. As evident in other countries, a health insurance policy to cover dietitians' visits within a multidisciplinary health care team might be a prospective approach to scale up evidence based WM practices among adult population in the UAE.

\section{Conflicts of Interest}

The authors report no conflicts of interest. 


\section{Authors' Contributions}

Amita Attlee participated in conception and design; acquisition of data; analysis and interpretation of data; drafting and revising the article critically for important intellectual content; overall scientific management. Nour Atmani, Viktor Stromtsov, Fatima Ali, Rim Tikarly, Sarah Ryad, and Ghada Salah participated in acquisition of data; analysis and interpretation of data; drafting the manuscript. Hayder Hasan participated in analysis and interpretation of data and revising the article critically for important intellectual content. Reyad Obaid participated in conception and design; analysis and interpretation of data; drafting and revising the article critically for important intellectual content.

\section{Acknowledgments}

The authors are grateful to Dr. Ashraf Ahmed Zaghloul, faculty member at the College of Health Sciences, for providing technical support in sampling and data analysis.

\section{References}

[1] American Medical Association, 2013, http://www.npr.org/ documents/2013/jun/ama-resolution-obesity.pdf.

[2] S. W. Ng, S. Zaghloul, H. I. Ali, G. Harrison, and B. M. Popkin, "The prevalence and trends of overweight, obesity and nutrition-related non-communicable diseases in the Arabian Gulf States," Obesity Reviews, vol. 12, no. 1, pp. 1-13, 2011.

[3] N. Farah, 75 per cent of UAE population is overweight, http:// gulfnews.com/news/gulf/uae/health/75-per-cent-of-uae-population-is-overweight-1.596687.2013.

[4] A. O. Musaigar, N. Abu-Aladeeb, and H. Qazaq, "Nutritional status of emiratiwomen in Al-Ain city, United Arab Emirates," Bahrain Medical Bulletin, vol. 22, no. 3, pp. 1-3, 2000.

[5] J. W. Anderson, E. C. Konz, and D. J. A. Jenkins, "Health advantages and disadvantages of weight-reducing diets: a computer analysis and critical review," Journal of the American College of Nutrition, vol. 19, no. 5, pp. 578-590, 2000.

[6] J. Payne-Palacio and D. Canter, The Profession of Dietetics, Lippincott Williams \& Wilkins, Baltimore, Md, USA, 2006.

[7] R. F. Kushner, "Weight loss strategies for treatment of obesity," Progress in Cardiovascular Diseases, vol. 56, no. 4, pp. 465-472, 2014.

[8] J. Kruger, D. A. Galuska, M. K. Serdula, and D. A. Jones, "Attempting to lose weight: Specific practices among U.S. Adults," The American Journal of Preventive Medicine, vol. 26, no. 5, pp. 402-406, 2004.

[9] C.-T. J. Lin, Z. Gao, and J.-Y. Lee, "Associations between self-reported weight management methods with diet quality as measured by the Healthy Eating Index-2005," Preventive Medicine, vol. 57, no. 3, pp. 238-243, 2013.

[10] P. A. Sharpe, M. L. Granner, J. M. Conway, B. E. Ainsworth, and M. Dobre, "Availability of weight-loss supplements: results of an audit of retail outlets in a southeastern city," Journal of the American Dietetic Association, vol. 106, no. 12, pp. 2045-2051, 2006.

[11] S. Manning, A. Pucci, and N. Finer, "Pharmacotherapy for obesity: Novel agents and paradigms," Therapeutic Advances in Chronic Disease, vol. 5, no. 3, pp. 135-148, 2014.
[12] D. Rudolph, "Appetite stimulants in long term care: a literature review," The Internet Journal of Advanced Nursing Practice, vol. 11, no. 1, pp. 1-8, 2009.

[13] J. A. O’Dea and S. Abraham, "Knowledge, beliefs, attitudes, and behaviors related to weight control, eating disorders, and body image in Australian trainee home economics and physical education teachers," Journal of Nutrition Education, vol. 33, no. 6, pp. 332-340, 2001.

[14] P. M. Gordon, G. W. Heath, A. Holmes, and D. Christy, "The quantity and quality of physical activity among those trying to lose weight," American Journal of Preventive Medicine, vol. 18, no. 1, pp. 83-86, 2000.

[15] M. K. Serdula, A. H. Mokdad, D. F. Williamson, D. A. Galuska, J. M. Mendlein, and G. W. Heath, "Prevalence of attempting weight loss and strategies for controlling weight," Journal of the American Medical Association, vol. 282, no. 14, pp. 1353-1358, 1999.

[16] M. K. Serdula, D. F. Williamson, R. F. Anda, A. Levy, A. Heaton, and T. Byers, "Weight control practices in adults: Results of a multistate telephone survey," American Journal of Public Health, vol. 84, no. 11, pp. 1821-1824, 1994.

[17] L. A. Klos and J. Sobal, "Marital status and body weight, weight perception, and weight management among U.S. adults," Eating Behaviors, vol. 14, no. 4, pp. 500-507, 2013.

[18] D. W. Johnston and G. Lordan, "Weight perceptions, weight control and income: an analysis using British data," Economics \& Human Biology, vol. 12, no. 3, pp. 132-139, 2014.

[19] M. A. T. B. Reese, “Underweight: a heavy concern," Today's Dietitian, vol. 10, no. 1, p. 56, 2013.

[20] N. Aljefree and F. Ahmed, "Prevalence of cardiovascular disease and associated risk factors among adult population in the gulf region: a systematic review," Advances in Public Health, vol. 2015, Article ID 235101, 23 pages, 2015.

[21] European Nutrition and Health Report 2004, https://books .google.co.in/books?isbn=3805579055.

[22] F. J. M. Spikmans, J. Brug, M. M. B. Doven, H. M. Kruizenga, G. H. Hofsteenge, and M. A. E. van Bokhorst-van der Schueren, "Why do diabetic patients not attend appointments with their dietitian?" Journal of Human Nutrition and Dietetics, vol. 16, no. 3, pp. 151-158, 2003.

[23] K. M. Kolasa and K. Rickett, "Barriers to providing nutrition counseling cited by physicians: a survey of primary care practitioners," Nutrition in Clinical Practice, vol. 25, no. 5, pp. 502-509, 2010.

[24] C. Lorts and P. Ohri-Vachaspati, "Disparities in who receives weight-loss advice from a health care provider: does income make a difference?" Preventing Chronic Disease, vol. 13, no. 10, article E142, 2016.

[25] UAE population by nationality-Abu Dhabi Information Portal, May 2016, http://www.abudhabi2.com/uae-populationby-nationality/.

[26] M. Alameddine, L. Nasreddine, N. Hwalla et al., "Factors associated with consulting a dietitian for diabetes management: a cross-sectional study," BMC Health Services Research, vol. 13, no. 1, article 504, 2013.

[27] K. Fitzner, E. F. Myers, N. Caputo, and P. Michael, "Are health plans changing their views on nutrition service coverage?" Journal of the American Dietetic Association, vol. 103, no. 2, pp. 157-161, 2003. 
[28] H. I. Ali, R. M. Bernsen, S. Taleb, and B. Al Azzani, "Carbohydrate-food knowledge of Emirati and Omani adults with diabetes: results of a pilot study," International Journal of Diabetes and Metabolism, vol. 16, no. 1, pp. 25-28, 2008. 


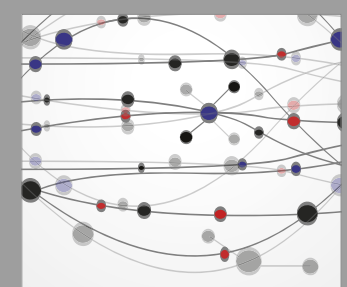

The Scientific World Journal
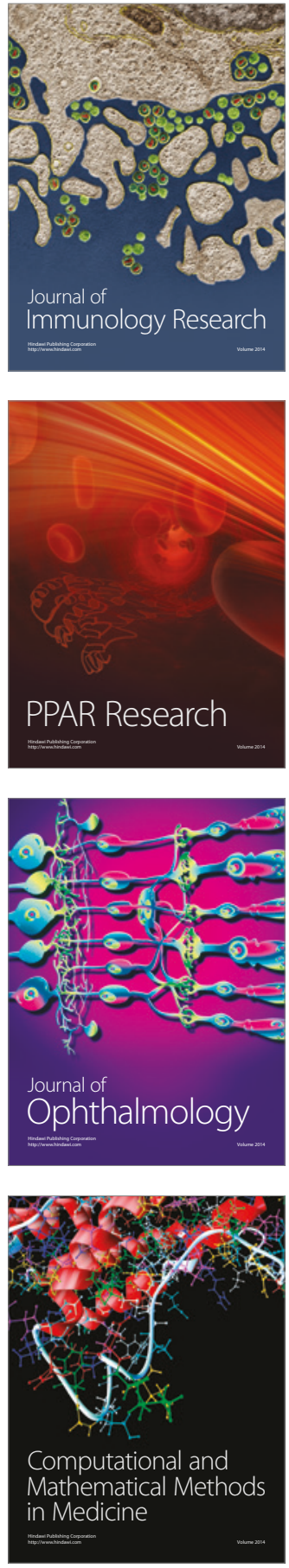

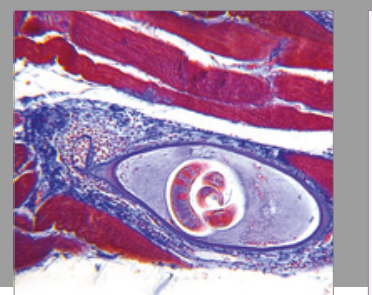

Gastroenterology Research and Practice
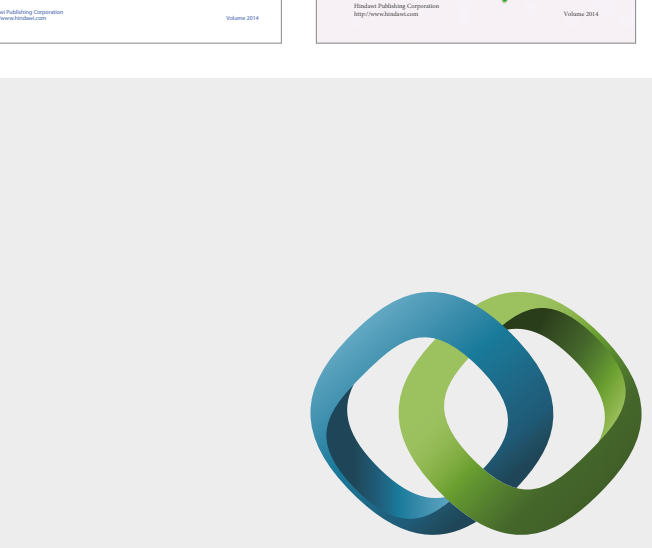

\section{Hindawi}

Submit your manuscripts at

https://www.hindawi.com
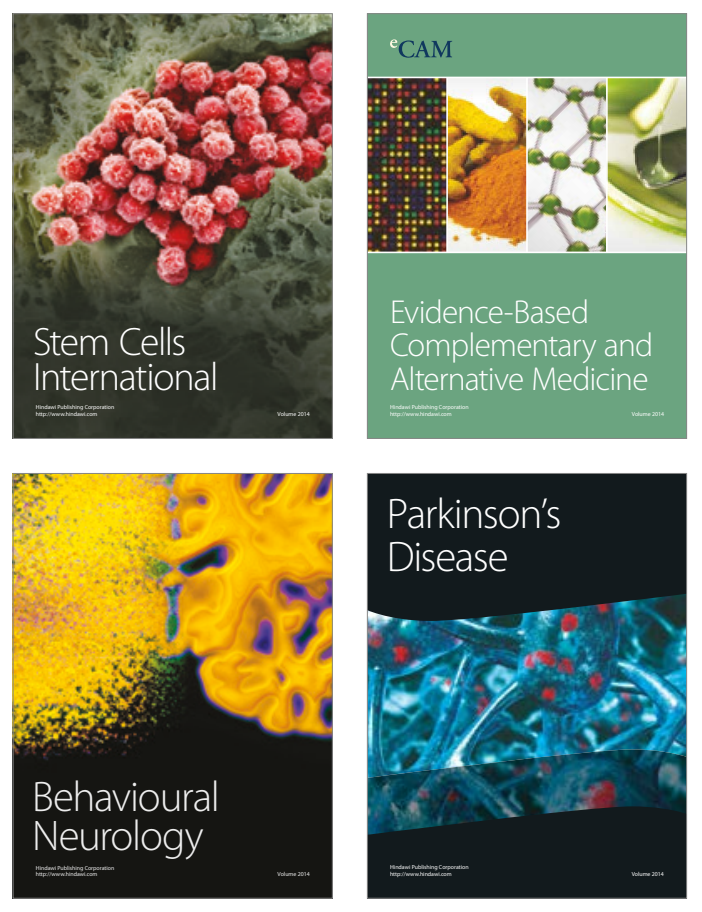
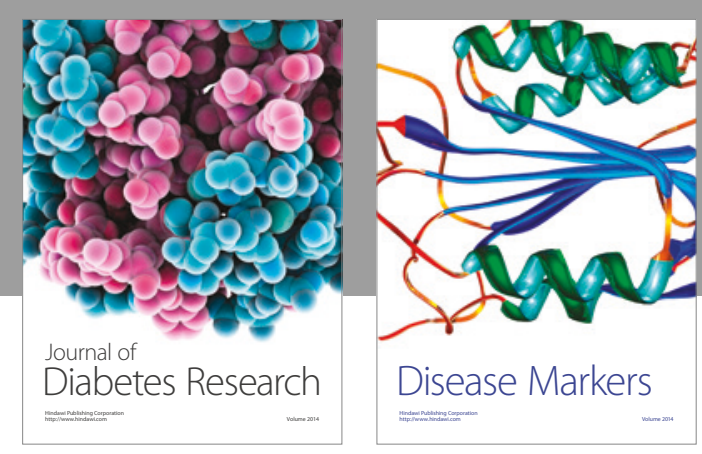

Disease Markers
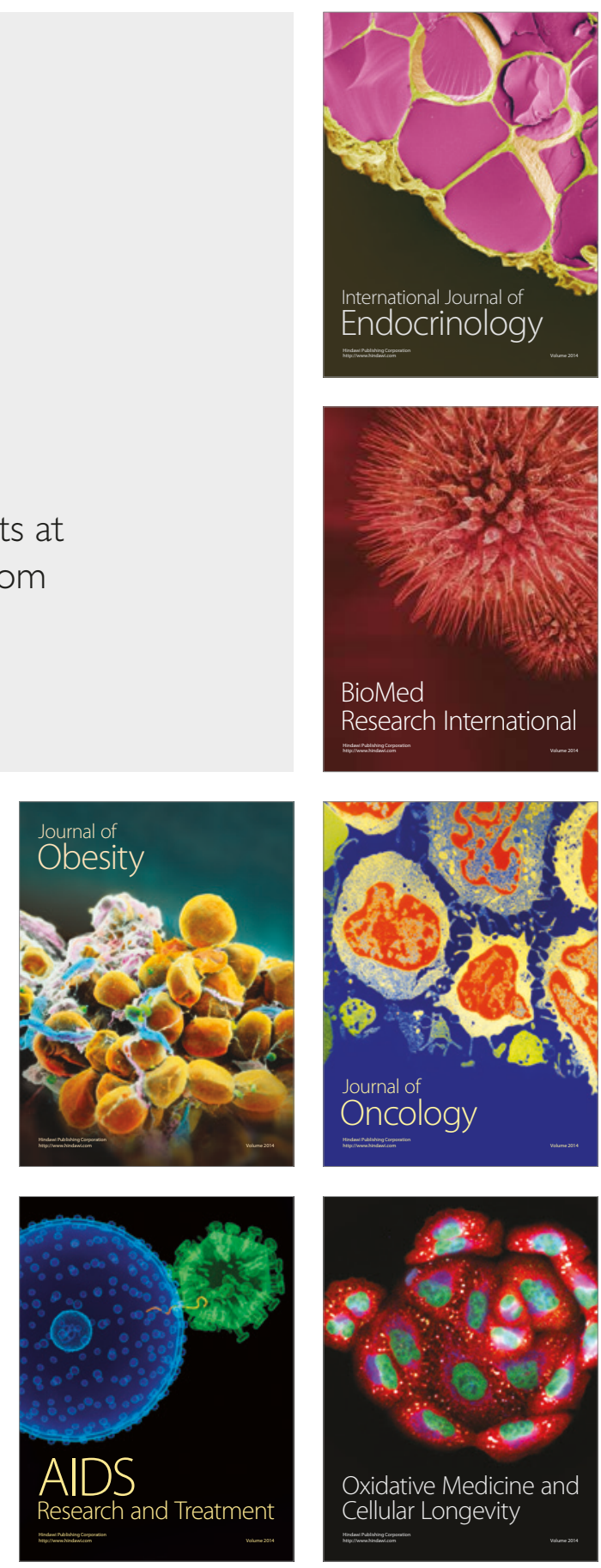